\title{
Trimetazidine for prevention of induced ischemia and reperfusion of guinea pig retina
}

This article was published in the following Dove Press journal:

Clinical Ophthalmology

23 December 2009

Number of times this article has been viewed

\author{
T Demirl \\ B Turgut' \\ I Ozercan ${ }^{2}$ \\ FC Gul' \\ $\mathrm{N}$ Ilhan ${ }^{3}$ \\ U Celiker \\ 'Department of Ophthalmology, \\ ${ }^{2}$ Department of Pathology, \\ ${ }^{3}$ Department of Biochemistry, Firat \\ University School of Medicine, \\ Elazig, Turkey
}

Correspondence: Burak Turgut Assistant Professor of Ophthalmology, Firat University School of Medicine, Department of Ophthalmology,

Elazig, Turkey

Tel +904242333555

Fax +904242388096

Email drburakturgut@gmail.com
Objective: Trimetazidine (TMZ) has been used to protect against ischemia/reperfusion (I/R) injury of many tissues. We aimed to evaluate the effect of TMZ during retinal I/R in a guinea pig model.

Study design/patients and methods: An experimental study in retinal I/R. Three groups of five guinea pigs were studied to include a control, placebo, and drug test groups. Prior to the application of 90 minutes of high intraocular pressure (IOP) to induce retinal ischemia followed by 24 hours of reperfusion, we applied intraperitoneal saline to the placebo group and $3 \mathrm{mg} / \mathrm{kg}$ of TMZ for the drug test group and repeated the injections at intervals of six hours for four cycles. Both eyes of the animals were enucleated at the end of the reperfusion period. Biochemical assay and histopathologic evaluation was performed on one randomly selected eye of each animal. The level of retinal-free malondialdehyde (MDA) and retinal layer thicknesses were determined and comparisons were then made with the control group.

Results: The mean free MDA level increased in the placebo group $(P=0.006)$ but not in the drug group $(P>0.05)$. We observed polymorphonucleated leukocyte infiltration, retinal edema and hydropic degeneration in the retina of the placebo group. However, significant histopathologic change was not observed in specimens of the drug group.

Conclusions: This study suggests TMZ has a beneficial effect on retinal lipid peroxidation and histopathologic changes due to I/R injury.

Keywords: ischemia/reperfusion, retina, trimetazidine

\section{Introduction}

Trimetazidine (1(2,3,4-trimethoxyl-benzyl) piperazine $\mathrm{HCl}$ [TMZ]) was introduced several years ago as an anti-ischemic drug devoid of hemodynamic activity. ${ }^{1} \mathrm{TMZ}$ has been reported as having antioxidant activity. ${ }^{2} \mathrm{TMZ}$ positively influences the energy metabolism, it reduces the utilization of fatty acids in favour of carbohydrates, the toxicity of oxygen and the inflammatory process. ${ }^{3} \mathrm{TMZ}$ has been demonstrated to limit acidosis and intracellular accumulation of sodium and calcium. A protective effect of TMZ on potassium permeability induced by oxygen free radicals has also been emphasized. ${ }^{4}$ TMZ inhibits platelet adhesion-aggregation, neutrophil infiltration and the generation or activity of oxygen-derived free radicals. ${ }^{5}$

Trimetazidine has been used to protect a variety of tissues from I/R injury including; myocardium, kidney, intestine, and liver. ${ }^{6-9}$ Free radicals play a role in the genesis of reperfusion-induced injury and that inhibition or scavengering of these highly cytotoxic intermediates may control potentially dangerous retinal injury. ${ }^{10}$ The protective effect of TMZ in retinal I/R injury has been previously reported. ${ }^{11}$ 
According to its severity and duration retinal ischemia may result in the death of affected cells. Initially the ischemic retinal cells enter a phase of reversible injury, when timely reperfusion results in the survival of retinal cells that would otherwise die. Despite reperfusion, there is a direct correlation with duration of ischemia and the degree of retinal cell death. The human retina is not resistant to ischemic injury. The condition is encountered in occlusions of the retinal artery and vein, diabetes, sickle cell disease, inflammatory diseases, and perhaps most dramatically in retinopathy of prematurity. ${ }^{12-15}$ Also a number of triggers, in addition to free radicals have been suggested to be responsible for the genesis of reperfusion induced retinal damage. These include; stimulation of the platelet activating factor, release of lysophosphatides, and disturbances of potassium, sodium, and calcium conductance. ${ }^{10}$

In the present study, we examined the effects of acute retinal $I / R$ injury in a guinea pig model and the effects of $\mathrm{TMZ}$ on this process.

\section{Materials and methods}

Fifteen male, pigmented guinea pigs weighing 420-580 g were selected for this study and were randomly divided into three groups. Ischemia and reperfusion were not induced and no drug was administered to the control group. During ischemia and reperfusion periods, normal saline and TMZ were administered to the placebo and drug groups, respectively.

Procedures used in this investigation conformed to the Animals in Ophthalmic and Vision Research (ARVO) statement for the Use of the Animals in Ophthalmic and Vision Research. The animals were housed in wire-bottomed cages at room temperature with a 12-hour light-dark cycle. All animals were fed with standard rat chow although they were given only water 12 hours before surgery. Anesthesia was induced in the test animals using an intraperitoneal injection of $6 \%$ sodium pentobarbital $(0.1 \mathrm{~mL} / 100 \mathrm{~g}$ body weight $)$. Proparacaine- $\mathrm{HCl}(0.05 \%)$ was administered as topical anesthetic to both eyes of the animals prior to surgical interventions. A previously described pressure induced retinal ischemia was performed in the placebo and drug groups. ${ }^{16}$ Accordingly both anterior ocular chambers of each animal of the placebo and drug test groups were cannulated with a 27 gauge needle connected to a bottle of normal saline and the bottle was rapidly lifted to a height of $205 \mathrm{~cm}$ in order to raise the intraocular pressure to $150 \mathrm{mmHg}$ and sustained for 90 min Reperfusion was established by lowering the saline bottle to the eye level. The eyes were decanulated and underwent reperfusion for 24 hours. Normal saline (1 mL) and TMZ (Vastarel, Servier, France), $3 \mathrm{mg} / \mathrm{kg}$ were diluted with $3 \mathrm{~mL} 0.9 \% \mathrm{NaCl}$ solution were injected intraperitoneally 15 minutes prior the induction of ischemia to the animals of the drug group. Similarly $4 \mathrm{~mL}$ of saline was injected intraperitoneally into animals of the placebo group. This was repeated every six hours for 24 hours (four in total). The dosage of TMZ was administered according to the model described by Ozden and colleagues. ${ }^{11}$ After the reperfusion period of the placebo and drug groups, the animals were reanesthetized and both eyes of all the animals were enucleated. Similarly both eyes of the animals belonging to the control group were also enucleated. The animals were sacrificed by intracardiac thiopental sodium $(50 \mathrm{mg} / \mathrm{kg})$ at the end of the experiment. One eye of each animal was prepared for biochemical analysis and the other underwent histopathological evaluation. For biochemical analysis the enucleated eyes were immediately dissected coronally through the pars plana and after removal of the vitreous humor, the retinal tissue was dissected from the choroidea and stored at $-80^{\circ} \mathrm{C}$ until the biochemical assay was undertaken.

For determination of malondialdehyde (MDA) levels in the retinal tissue, the samples were homogenized. $50 \mathrm{mg}$ of the homogenate was added to $0.1 \mathrm{~mL}$ of $0.5 \mathrm{M} \mathrm{HClO}_{4}$ and $0.4 \mathrm{~mL}$ of distilled water. The addition of perchloric acid was necessary to precipitate proteins and release the MDA bound to the amino groups of proteins and other amino compounds. The samples were then centrifuged at $4500 \times \mathrm{g}$ for five minutes. Samples $(20 \mu \mathrm{l})$ of the supernatant were separated using high-performance liquid chromatography (HPLC). HPLC separations were accomplished at room temperature, using a Cecil liquid chromatography system (Series 1100) consisting of a sample injection valve (Cotati 7125) with a $20 \mu 1$ sample loop, an ultra-violet (UV, at $254 \mathrm{~nm}$ ) spectrophotometric detector (Cecil 68174), integrator (HP 3395) and a Supelcosil LC18 (5 $\mu \mathrm{m}$ particle and $80 \mathrm{~nm}$ pore size $)$ column $(250 \mathrm{~cm} \times$ $4.6 \mathrm{~mm} \mathrm{ID}$ ) with mixture of $30 \mathrm{mmol} \mathrm{KH}_{2} \mathrm{PO}_{4}$ and methanol (in the ratio 65:35 the $\mathrm{pH}$ was adjusted to 4 using $\mathrm{H}_{3} \mathrm{PO}_{4}$ ), mobile phase at $1.5 \mathrm{~mL}$ minute $^{-1}$ flow rate. ${ }^{17,18}$

Histopathologic evaluation was performed on sections obtained in the vertical meridian and the inferior portion of the eyeball without knowing which treatment was given. The sections were fixed in $10 \%$ formaline. Paraffin sections with $5 \mu \mathrm{m}$ thickness were prepared and stained with hematoxylin and eosin. Evaluation of the histopathologic specimens was by the pathologist conducting the trial without knowing which treatment was given using an Olympus BX50 light microscope and color photomicrographs were obtained. Quantification of the degree of histopathologic damage that 
was induced by $\mathrm{I} / \mathrm{R}$ was made by measuring thickness of the retinal layers. The mean value for these measurements, taken in four adjacent areas of the inferior retina within $1 \mathrm{~mm}$ of the optic nerve, was calculated. The measurements were made with an ocular micrometer at $400 \times$ magnification.

We presented the free MDA values and the tissue thicknesses of each group as the mean \pm standard deviation (SD) and the statistical analysis was made using a Mann-Whitney $U$ test. We considered a $P$ value $<0.05$ as significant.

\section{Results}

The mean free MDA level of the control, the placebo and the drug groups was $5.13 \pm 0.92,9.45 \pm 1.82$ and $5.25 \pm$ $1.02 \mathrm{nmol} \mathrm{MDA} / \mathrm{g}$ wet tissue, respectively. The mean free MDA level of the placebo group was significantly higher versus the control and drug groups $(P=0.004, P=0.006$, respectively). When we compared the control group with the drug group the mean free MDA level was not statistically different $(P>0.05)$.

The thickness of the retinal layers of the groups is presented in Table 1 and Figure 1. The histopathologic specimens of the control and the placebo group were compared. Observed differences were mainly in the inner retina of the placebo group. Prominent edema in the inner plexiform and ganglion cell layers, polymorphonuclear leucocyte (PMNL) infiltration and vacuolated spaces, hydropic degeneration, pyknosis particularly in the inner nuclear and ganglion cell layers were the main changes that were observed in the placebo group when compared to the control group (Figure 2). Additionally prominent edema was also observed in the outer plexiform and outer nuclear layers of the placebo group. Only mild edema was observed in the inner retina of the drug group (Figure 3).

The main findings observed in some histopathologic specimens of the drug group were mild edema of the photoreceptor, outer nuclear and inner plexiform layers and hydropic degeneration of a few cells in the inner nuclear and ganglion cell layers (Figure 3 ). The pathologic findings noticed in the placebo group were severe edema was observed mainly in the inner retina.

\section{Discussion}

During ischemia and reperfusion in a number of tissues such as intestine, central nervous system, and heart, oxygenderived free radicals are thought to play an important role in the genesis of tissue injury. Endogenous scavengering mechanisms may be overwhelmed by a burst of radical production occurring during reperfusion or reoxygenation. ${ }^{19-22}$ Primary ocular diseases or ocular complications of systemic diseases may cause retinal ischemia that results in cell death by the destruction of cellular elements such as DNA, protein, and cell membrane. ${ }^{23}$

As high fatty acid oxidation rates markedly decrease glucose oxidation, one approach to increase glucose oxidation is to inhibit fatty acid oxidation. TMZ primarily acts by inhibiting fatty acid oxidation and thereby stimulating glucose oxidation. Earlier studies demonstrated that TMZ inhibits mitochondrial palmitoly carnitine oxidation, while only slightly altering pyruvate oxidation and preserving mitochondrial oxidative functions thereby significantly stimulating glucose oxidation. ${ }^{24}$ Stimulation of glucose oxidation improves the coupling of glycolysis to glucose oxidation, resulting in a decrease in proton production and a decrease in intracellular acidosis during ischemia. ${ }^{24}$ Charlton and colleagues ${ }^{25}$ studied the possible antioxidant effects of TMZ by using rat hearts that were perfused in ischemic conditions. The oxidative damage was measured in terms of enzymatic activity of MDA and MDA levels were found to decrease in their study. In the present study TMZ has inhibited the increase in MDA values of the retinal tissue which has undergone $I / R$. TMZ has also been reported to reduce the tissue formation of MDA. ${ }^{26}$ It reduces the oxidative stress which occurs during the reoxygenation phase of the reperfusion, evaluated as a limited reduction in glutathione release. ${ }^{27}$

In order to determine thresholds for irreversible cellular injury in the rat retina, timed acute no flow ischemic episodes of 30-180 minutes duration were produced by elevation of intraocular pressure (IOP) above systolic pressure. Quantitation of irreversible degeneration and cell loss following a two-week postischemic interval was performed by computer assisted measurements from histologic sections.

Table I The thickness of the retinal layers $(\mu \mathrm{m})$

\begin{tabular}{lllllll}
\hline Groups & GCL & IPL & INL & OPL & ONL & PL \\
\hline Control & $8.0 \pm 1.42$ & $14 \pm 1.85$ & $10.75 \pm 1.67^{2}$ & $7.0 \pm 1.67$ & $12.0 \pm 2.09$ & $13.0 \pm 3.26$ \\
Placebo & $14.25 \pm 1.12^{1}$ & $20.2 \pm 3.58^{\prime}$ & $17.25 \pm 1.85$ & $12.25 \pm 1.0^{\prime}$ & $15.85 \pm 1.02^{\prime}$ & $18.25 \pm 3.791$ \\
Drug & $9.0 \pm 2.05$ & $15.5 \pm 2.09$ & $11.75 \pm 1.89^{3}$ & $8.5 \pm 1.36$ & $14.5 \pm 1.89$ & $15.25 \pm 1.85$ \\
\hline
\end{tabular}

Notes: ${ }^{1} P<0.05$ for placebo vs drug and control, ${ }^{2} P<0.01$ for placebo vs control, ${ }^{3} P<0.05$ for placebo vs drug.

Abbreviations: GCL, ganglion cell layer; IPL, inner plexiform layer; INL, inner nuclear layer; OPL, outer plexiform layer; ONL, outer nuclear layer; PL, photoreceptor layer. 


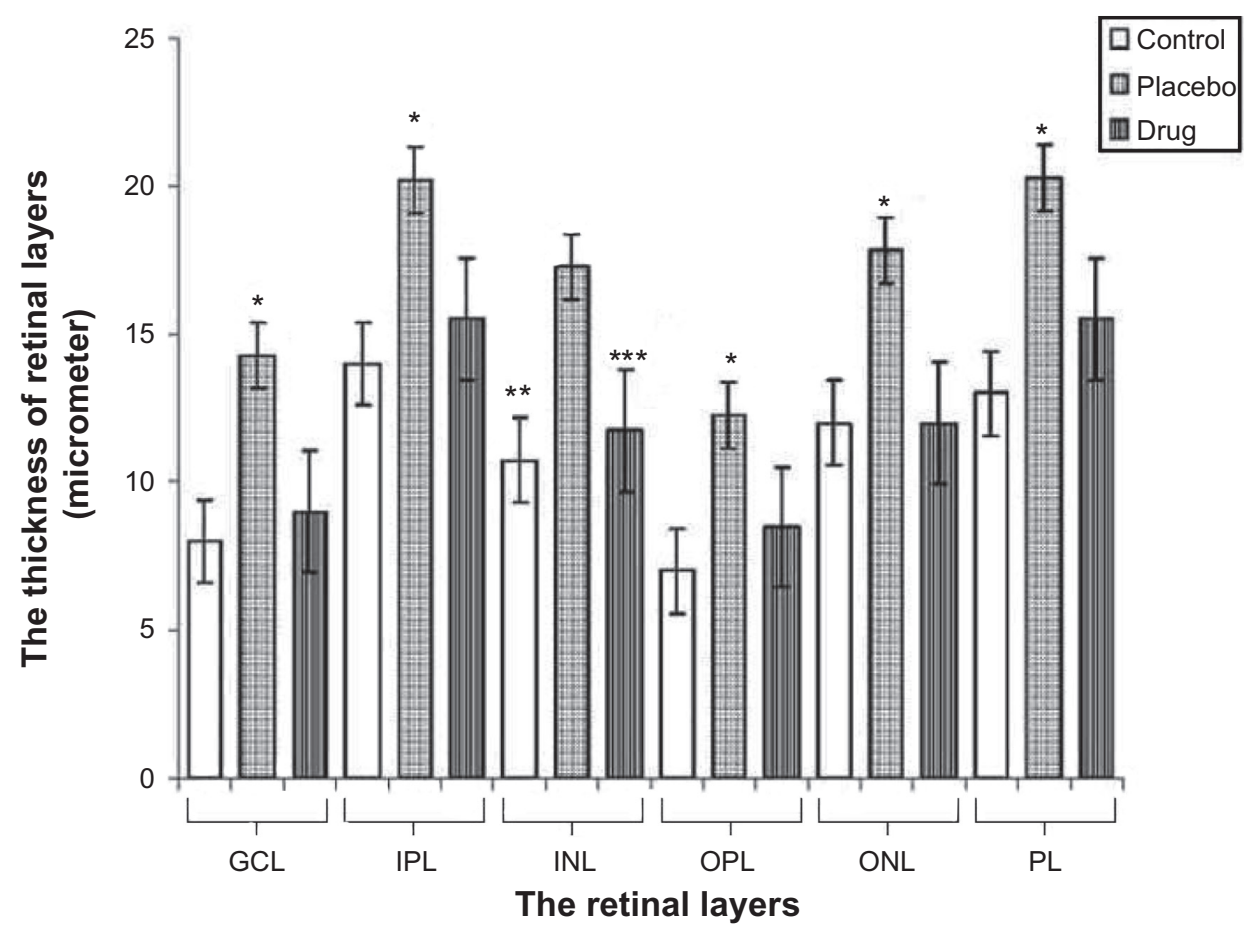

Figure I The graphical changes of thickness of the retinal layers.

Abbreviations: GCL, ganglion cell layer; IPL, inner plexiform layer; INL, inner nuclear layer; OPL, outer plexiform layer; ONL, outer nuclear layer; PL, photoreceptor layer.

Changes of thickness of retinal layers and linear cell density were determined for ischemia of selected durations. ${ }^{15}$ A reduction in the retinal thickness has been reported in a recent study in which eight days of reperfusion period was performed. Nevertheless, increase in the retinal thickness due to retinal edema has been described in animal studies with reperfusion periods of 24 hours or shorter duration after an ischemic period of 90 minutes. ${ }^{28,29}$ The result of our study, indicating the increase in the retinal thickness, is consistent with studies in which 24 hours or shorter reperfusion periods

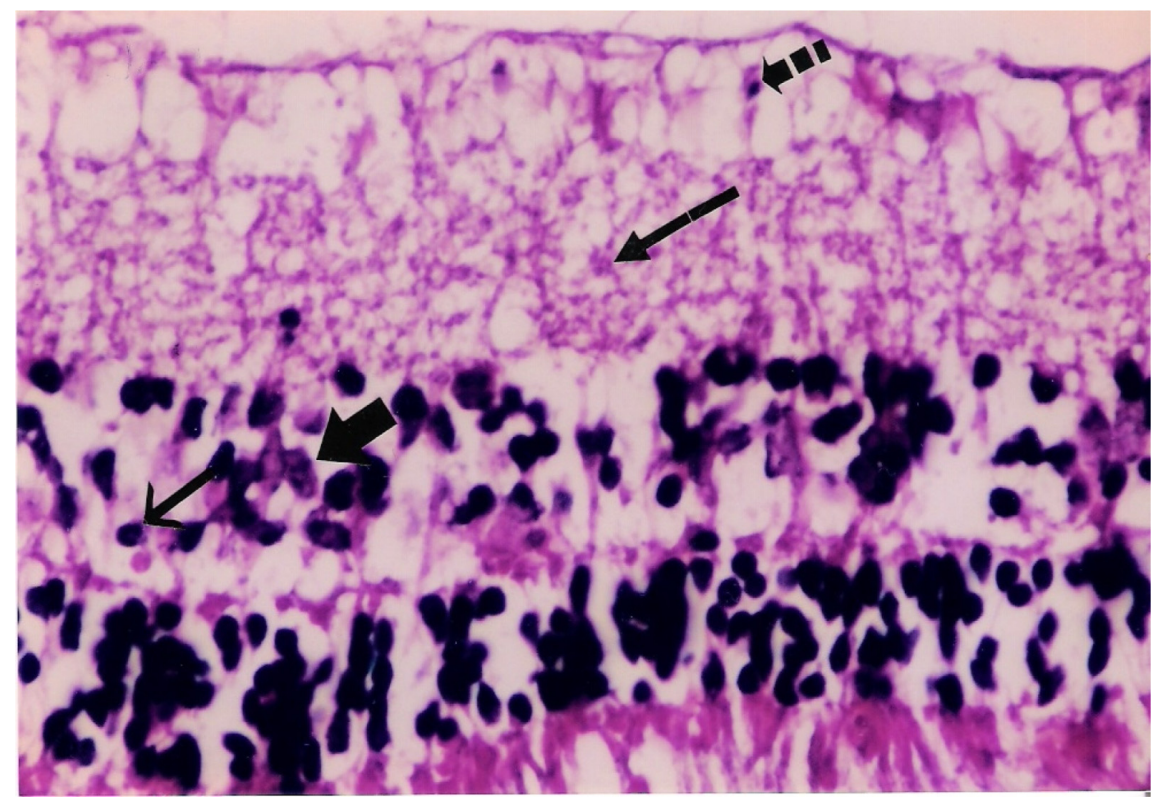

Figure 2 Placebo: Microphotograph of degeneration of retinal ganglion cells (broken arrow), edema of inner plexiform layer (long arrow), pyknotic cells in inner nuclear layer (short arrow) and polymorphonuclear leukocytes (thick arrow).

Notes: Hematoxylin and eosin $400 \times$ magnification. 


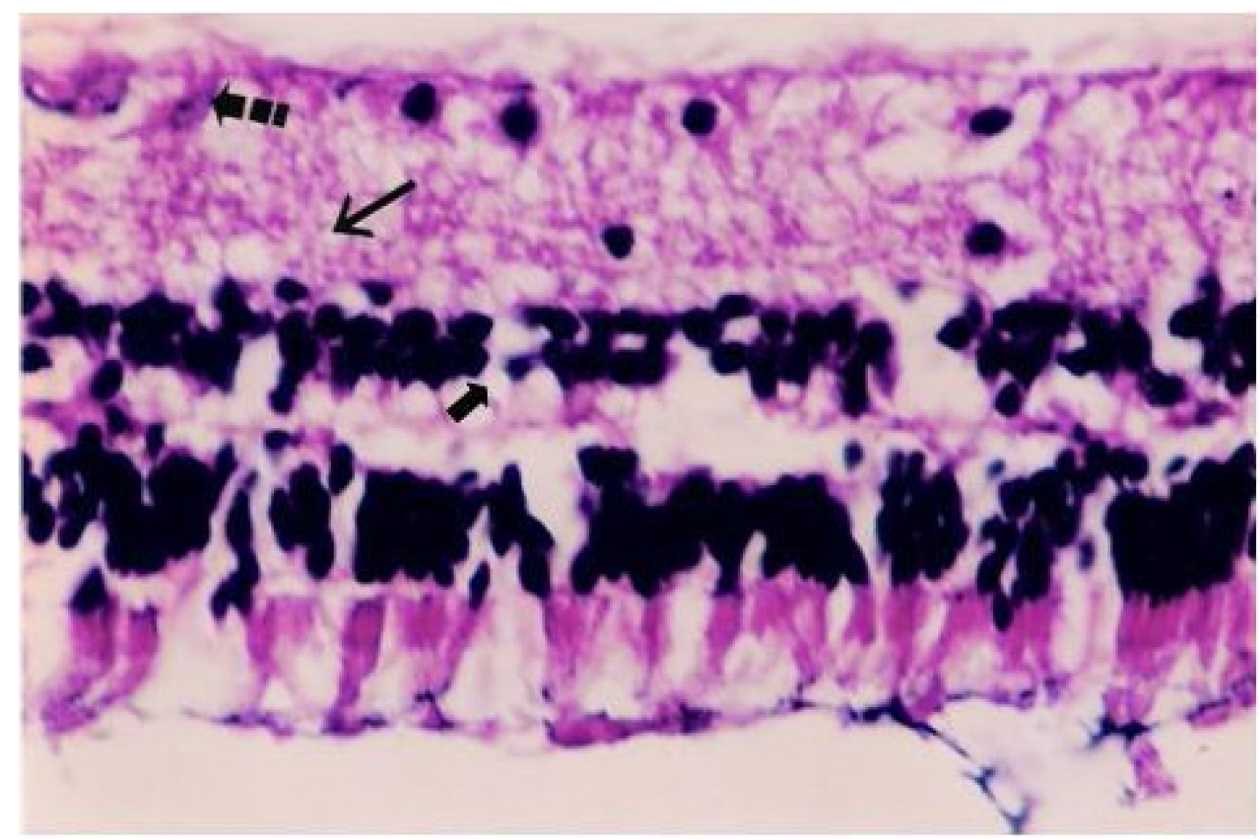

Figure 3 Drug: Histological photograph of hydropic degeneration of a few ganglion cells (broken arrow), slight edema of inner plexiform layer (long arrow), and hydropic degeneration of a few cells in inner nuclear layer (short arrow).

Notes: Hematoxylin and eosin $400 \times$ magnification.

have been been set up. TMZ has been demonstrated to limit the intracellular accumulation of sodium and calcium. A protective effect of TMZ on potassium permeability induced by oxygen free radicals has also been emphasized. ${ }^{4}$ We considered TMZ limited edema formation in retina by stabilizing intracellular electrolyte levels and due to its antiinflammatory action. We observed significant histopathologic changes in the inner nuclear and ganglion cell layers of the placebo group similar to a previous study in which depletion of cytoplasmic organelles, swelling of mitochondria and enlargement of endoplasmic reticulum have been observed in the ganglion cells by electron microscopy after retinal ischemia. ${ }^{30}$ When the ischemic duration was extended to 60 minutes, reperfusion of the previously ischemic retina increased the edema formation in the inner plexiform layer. Increasing the ischemia to $90 \mathrm{~min}$ caused serious retinal edema, observed at a maximum value even after 24 hours of reperfusion. ${ }^{10}$

Under certain conditions of altered physiology, the neutrophil leukocytes may react in a manner that leads to tissue injury. The tissue damage resulting from retinal ischemia activates a cascade of events which represents an inflammatory response that occurs independently of any improvement in retinal reoxygenation. ${ }^{31}$ The inflammatory reaction is an important source of oxygen-free radicals. Large amounts of superoxide radicals are secreted by activated phagocytic leukocytes and radicals are also formed as a byproduct during prostaglandin and leukotriene biosynthesis. ${ }^{19} \mathrm{TMZ}$ reduces the infiltration of neutrophils in the risk area. ${ }^{26}$ Szabo and colleagues ${ }^{29}$ demonstrated that neutrophil leukocyte infiltration could be observed after 90 minures of ischemia followed by 24 hours of reperfusion in the rat retina. In addition, antioxidant agents could significantly reduce the incidence of neutrophil leukocyte infiltration. Histopathologic changes such as severe edema, vacuolated spaces and PMNL infiltration mainly in the inner retina of the placebo group are consistent with our findings. It was reported that TMZ could have a favorable effect on myocardial ischemia by reducing neutrophil leukocyte infiltration which, in turn is responsible for myocardial necrosis. ${ }^{25}$ In a previous study no neutrophil infiltration in the retinal tissue was observed in any of the TMZ-treated rats. ${ }^{11}$ TMZ's mechanism of action on the infiltration of neutrophils is still unclear. Because the neutrophil penetration depends on chemotactic agents and the expression of adhesion molecules stimulated by cytokines.

In conclusion, TMZ has a significant role in combatting the consequences of retinal lipid peroxidation and it diminishes the formation of retina edema and degenerative changes during ischemia and reperfusion. Although the sample size might be considered as a limitation of the present study, our results indicate the clinical application of $\mathrm{TMZ}$ in retinal 
vascular pathologies related to ischemia and reperfusion injury may have beneficial effects.

\section{Acknowledgments}

Those involved in conducting the study would like to thank those who assisted with the collection of data, typing, editing of manuscript, its preparation, for review, and approval of the final manuscript. The authors report no conflicts of interest in this work.

\section{References}

1. Sellier P, Audoin P, Rayen B, et al. Acute effects of trimetazidine evaluated by exercise testing. Eur J Clin Pharmacol. 1987; 33:205-207.

2. Maupoil V, Rochette L, Tabard A, Clauser P, Harpey C. Evolution of free radical formation during low-flow ischemia and reperfusion in isolated rat heart. Cardiovasc Drug Ther. 1990;4:791-796.

3. Fantini E, Demaison L, Sentex E, Grynberg A, Athias P. Some biochemical aspects of the pprotective effect of trimetazidine on rat cardiomyocytes during hypoxia and reoxygenation. J Mol Cell Cardiol. 1994;26:949-958.

4. Fitoussi M, Rochette L, Brlet J. Incidences fonctionnelles et metaboliues d'un pretraitement par la trimetazidine u niveau du coeur de rat. Arch Mal Coeur et Visseux. 1985;78:460-465.

5. Harpey C, Clauser P, Labrid C, Freyria JL, Poririer J. Trimetazidine, a cellular anti-ischemic agent. Cardiovasc Drug Rev. 1989; 4:292-312.

6. Williams FM, Tanda K, Kus M, Williams TJ. Trimetazidine inhibits neutrophil accumulation after myocardial ischemia and reperfusion in rabbits. J Cardiovasc Pharmacol. 1993;22:828-833.

7. Ozden S, Aybek Z, Saydam N, et al. Cytoprotective effect of trimetazidine on 75 min warm renal ischemia-reperfusion injury in rats. Eur Surg Res. 1998;30:227-234.

8. Tetik C, Ozden A, Calli N, et al. Cytoprotective effect of trimetazidine on 60 minutes of intestinal ischemia-reperfusion injury in rats. Transplant Int. 1999;12:108-112.

9. Tsimoyiannis EC, Moutesidou KJ, Moschos CM, et al. Trimetazidine for prevention of hepatic injury induced by ischemia and reperfusion in rats. Eur J Surg. 1993;159:89-93.

10. Hayreh SS, Weingeist TA. Experimental occlusion of the central retinal artery of the retina: IV: Retinal tolerance time to acute ischemia. $\mathrm{Br} J$ Ophthalmol. 1980;64:818-825.

11. Ozden S, Kildaci B, Muftuoglu S, Cakar N, Yıldırım C. Effect of trimetazidine on retinal ischemia/reperfusion injury in rats. Ophthalmologica. 2001;215:309-317.

12. Kroll AJ. Experimental central retinal artery occlusion. Arch Ophthalmol. 1968;79:453-469.

13. Hoff M, Gouras P. Tolerance of mammalian retina to circulatory arrest. Docum Ophthal Proc Ser. 1973;2:57-63.
14. Blair NP, Shaw WE, Dunn R Jr, et al. Limitation of retinal injury by vitreoperfusion initiated after onset of ischemia. Arch Ophthalmol. 1991;109:113-118.

15. Hughes WF. Quantitation of ischemic damage in the rat retina. Exp Eye Res. 1991;53:573-582.

16. Alagoz G, Celiker U, Ilhan N, Yekeler H, Demir T, Celiker H. L-carnitine in experimental retinal ischemia-reperfusion injury. Ophthalmologica. 2002;216:144-150.

17. Karatas F, Karatepe M, Baysar A. Determination of free in human serum by high performance liquid chromatography. Anal Biochem. 2002;311:76-79.

18. Cordis GA, Bagchi D, Maulik N, Das DK. High-performance liquid chromatographic method for the simultaneous detection of malondialdahyde, acetaldehyde, formaldehyde, acetone and propionaldahyde to monitor the oxidative stress in heart. J Chromat A. 1994; 661:181-191.

19. Kontos HA. Oxygen radicals in cerebral vascular injury. Circ Res. 1985;57:508-516

20. Parks DA, Bulkley GB, Granger DN, Hamilton SR, McCord JM. Ischemia injury in the cat small intestine: Role of superoxide radicals. Gastroenterology. 1982;82:9-13.

21. McCord JM. Oxygen-derived free radicals in post-ischemic tissue injury. N Engl J Med. 1985;312:159-163.

22. Bolli R, Jeroudi MO, Patel BS, et al. Marked reduction of free radical generation and contractile dysfunction by anti-oxidative therapy begun at the time of reperfusion: Evidence that myocardial stunning is a manifestation of reperfusion injury. Circ Res. 1989;65:607-622.

23. Choi DW. Glutamate neurotoxicity: A three stage process. In: Guidotti A, editor. Neurotoxicity of Amino Acids. FIDIA Research Foundation Symposium Series. New York, NY: Raven Press; 1991. p. 235-242.

24. Lopaschuk GD, Kozak R. Trimetazidine inhibits fatty acid oxidation in the heart. J Mol Cell Cardiol. 1998;30:A112.

25. Charlton V, Boucher F, Clauser P. Effect of a 5-day trimetazidine pretreatment in a model of ischeamic and reperfused isolated rat heart: spin trapping experiments. In: Ement I, editor. Antioxidants in Therapy and Preventive Medicine. New York, NY: Plenum Press; 1990. p. 377-382.

26. Ceconi C, Cargnoni A, Pasini E, Curello S, Ferrari R. Eveulation of phospholipid peroxidation as malondialdehyde during myocrdial ischemia and reperfusion injury. Med J Physiol. 1991;260:1057-1061.

27. Cargnoni A, Pasini E, Ceconi C, Curello S, Ferrari R. Insight into cytoprotection with metabolic agents. Eur Heart J Supplements. 1999;1:40-48.

28. Ophir A, Berenshtein E, Kitrossky N, Averbukh E. Protection of the transiently ischemic cat retina by zinc-desferrioxamine. Invest Ophthalmol Vis Sci. 1994;35:1212-1222.

29. Szabo ME, Droy-Lefaix MT, Doly M, Carre C, Braquet P. Ischemia and reperfusion induced histologic changes in the rat retina. Invest Ophthalmol Vis Sci. 1991;32:1471-1474.

30. Shakib M, Ashton N. Part II: Ultrastructural changes in focal retinal ischemia. Br J Ophthalmol. 1966;50:325-384.

31. Briggs RT, Robinson JM, Arnovsky ML, Karnovsky MJ. Superoxide production by polymorphonuclear leukocytes. Histochemistry. 1986;84:371-376.
Clinical Ophthalmology

\section{Publish your work in this journal}

Clinical Ophthalmology is an international, peer-reviewed journal covering all subspecialties within ophthalmology. Key topics include: Optometry; Visual science; Pharmacology and drug therapy in eye diseases; Basic Sciences; Primary and Secondary eye care; Patient Safety and Quality of Care Improvements. This journal is indexed on Submit your manuscript here: http://www.dovepress.com/clinical-ophthalmology-journal

\section{Dovepress}

PubMed Central and CAS, and is the official journal of The Society of Clinical Ophthalmology (SCO). The manuscript management system is completely online and includes a very quick and fair peer-review system, which is all easy to use. Visit http://www.dovepress.com/ testimonials.php to read real quotes from published authors. 